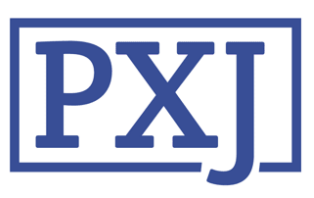

Patient Experience Journal

Volume 3 | Issue 1

Article 7

2016

\title{
Patient perceptions of an AIDET and hourly rounding program in a community hospital: Results of a qualitative study
}

Tosha Allen

Genesis Health System

Tyne Rieck

Genesis Health System

Stacie Salsbury

Palmer Center for Chiropractic Research

Follow this and additional works at: https://pxjournal.org/journal

Part of the Critical Care Nursing Commons, Health and Medical Administration Commons, Health Policy Commons, Health Services Administration Commons, Health Services Research Commons, Medical Education Commons, Nursing Administration Commons, and the Other Nursing Commons

\section{Recommended Citation}

Allen T, Rieck T, Salsbury S. Patient perceptions of an AIDET and hourly rounding program in a community hospital: Results of a qualitative study. Patient Experience Journal. 2016; 3(1):42-49. doi: 10.35680/ 2372-0247.1115.

This Article is brought to you for free and open access by Patient Experience Journal. It has been accepted for inclusion in Patient Experience Journal by an authorized editor of Patient Experience Journal. 


\section{Patient perceptions of an AIDET and hourly rounding program in a community hospital: Results of a qualitative study}

\section{Cover Page Footnote}

The authors thank the patients who participated in this study and offer a special acknowledgement to Sarah Castro, MPH, Research Support Liaison, Genesis Health System, for her patience and attention to this research. The authors received funding from the Genesis Research Promotion Funds to purchase voice recorders for this study. Excerpts from this study were presented on April 8, 2015, at a mini-session during the 2015 Beryl Institute Patient Experience Conference in Dallas, TX, entitled Patient Perception of the Hospital Experience: AIDET, Hourly Rounding and Overall Experience. This article is associated with the Culture \& Leadership lens of The Beryl Institute Experience Framework. (http://bit.ly/ ExperienceFramework). You can access other resources related to this lens including additional PXJ articles here: http://bit.ly/PX_CultureLeadership 


\title{
Patient perceptions of an AIDET and hourly rounding program in a community hospital: Results of a qualitative study \\ Tosha I. Allen, Genesis Health System, allent@genesishealth.com \\ Tyné Rieck, Genesis Health System, rieckt@genesishealth.com \\ Stacie Salsbury, Palmer Center for Chiropractic Research,stacie.salsbury@palmer.edu
}

\begin{abstract}
Quantitative evidence links patient satisfaction scores to the use of communication strategies such as AIDET (Acknowledge, Introduce, Duration, Explanation, and Thank you) and Hourly Rounding. However, little is known about patient perceptions of these tools in regards to their hospital experience. Qualitative interviews were conducted with a convenience sample of 14 adult medical/surgical inpatients in one mid-sized, community hospital, following hospital discharge. The interview data was transcribed and opened coded, utilizing constant comparison to identify common themes. Themes emerged in four topical areas: (a) patient experience of hospitalization, (b) AIDET, (c) Hourly Rounding, and (d) unexpected findings. Patients placed significant value on having their emotional needs met by staff during their hospitalization. While patients felt hospital staff explained procedures well, but staff did not explain the illness or its treatment effectively. AIDET was found to be applied consistently; however patients did not understand the duration aspect of AIDET. Hourly Rounding with a purpose was not noticeable by patients; descriptions by patients of the practice included medication passes and vital checks. However, reduction of call light usage and sleep interruptions were mentioned. Unexpected findings included feelings of loneliness while hospitalized and inconsistent delivery of patient's pain relief regimens. The results overall suggest a focus on meeting emotional needs may be necessary to improve patient experiences in the hospital. More intentional use of AIDET and Hourly Rounding may help to maximize the benefit of these tools. Further research is warranted to validate findings from this study.
\end{abstract}

\section{Keywords}

AIDET, hourly rounding, patient experience, nurse-patient relations, health communication, hospitalization, quality of health care, patient satisfaction, qualitative methods

\section{Introduction}

The patient's experience in a hospital setting is a rising concern in the health care arena as value-based purchasing and Hospital Consumer Assessment of Health Care Providers and Systems (H-CAHPS) become organizational priorities. ${ }^{1}$ The patient experience encompasses every aspect of the hospital stay, from nurses to physicians to food services. Dempsey, Reilly, and Buhlman ${ }^{1}$ asserted that although patients interact with over 20 health care workers, most of the patient's time is spent with nurses and this shapes their inpatient experience. Organizations are seeking innovative ways boost satisfaction scores and improve the patient experience. ${ }^{2}$

Patient experience and satisfaction may fall short of the consumer's expectations, most often from a gap in communication. ${ }^{3}$ One communication tool used by numerous healthcare organizations is AIDET, which stands for Acknowledge, Introduce, Duration, Explanation, and Thank You (Table 1). The AIDET communication tool was created to help health care providers engage patients in their care, reduce patients' fear and anxiety, and build positive relationships with patients and families. ${ }^{4}$ The benefit of healthcare providers using the AIDET acronym when interacting with patients is that it may minimize miscommunication and, if implemented correctly, accurately, and with buy-in from leadership and employees, may raise patient satisfaction scores. $5 ; 6$

Hourly Rounding is another health communication best practice that can raise a patient's perception of care and improve the patient experience. ${ }^{4}$ Hourly rounding with purpose, in which the nurse checks the patient for the four P's - (a) pain, (b) potty, (c) position, and (d) possessions also may improve patient satisfaction, outcomes, and safety. ${ }^{7}$ Ford ${ }^{2}$ concluded that consistent hourly rounding does result in improved staff satisfaction due to reduction in call lights and more satisfied patients. Questions remain whether patients recognize the use of AIDET and Hourly Rounding and how they feel these health communication tools affect their hospital stay.

Patient Experience Journal, Volume 3, Issue 1 - Spring 2016 
Table 1. AIDET Elements Defined

\begin{tabular}{|l|l|}
\hline Element & Practice and Purpose \\
\hline Acknowledge & $\begin{array}{l}\text { Verbally and non-verbally (such as through eye contact) acknowledge the patient } \\
\text { and any family members or caregivers. Determine relationship of visitors before } \\
\text { sharing patient information. }\end{array}$ \\
\hline Introduce & $\begin{array}{l}\text { Introduce yourself to patient and family including Name, Job Title, Expertise (such } \\
\text { as certifications or years of experience), and Purpose of Visit. }\end{array}$ \\
\hline Duration & $\begin{array}{l}\text { Give a time expectation for the activity/reason for the visit. Give a time } \\
\text { expectation for waiting or when to expect next visit }\end{array}$ \\
\hline Explanation & $\begin{array}{l}\text { Explain what is going to happen, in plain language that the patient can easily } \\
\text { understand. Inform the next steps of the process. }\end{array}$ \\
\hline Thank & $\begin{array}{l}\text { Thank the patient or family. Used to show appreciation and give a positive ending } \\
\text { to the encounter. }\end{array}$ \\
\hline
\end{tabular}

Our hospital implemented AIDET and Hourly Rounding on five inpatient hospital units, yet the patient perception of these interventions remained undetermined. AIDET competencies were signed and each nursing staff member (RNs and CNAs) was observed three times using AIDET with actual patients. A robust hourly rounding process also was implemented on these units in which patient experience champions interviewed patients to ensure hourly rounding was taking place. Patient satisfaction and $\mathrm{H}$-CAHPS scores had moved in a positive direction and the insight of the patient was desired in regards to the application of AIDET, Hourly Rounding and the overall hospital stay. The purpose of this study was to examine the perceptions of recently discharged patients of the AIDET and Hourly Rounding program, along with other factors that contributed to a positive or negative overall evaluation of their hospital stay.

\section{Methods}

We conducted a descriptive study of patient perceptions of their hospitalization and the AIDET and Hourly Rounding using individual qualitative interviews. ${ }^{8}$ The setting was a 400 -bed community hospital in the Midwestern United States. We recruited a convenience sample of recently discharged inpatients from cardiac, surgical, and medical units. Inclusion criteria were: age $\geq 18$ years; inpatient or observation status; hospitalized 2-5 days; and hospital admission only once within the past 6 months. Exclusion criteria were: obstetric, behavioral health, hospice or outpatient admission; prisoners; and non-English speaking. Eligible patients were verbally consented after the principal investigator (TA) explained the study purpose, interview process, risks and benefits, and participant rights. Eligible participants were offered a $\$ 25.00$ gift card for their time. The Genesis Health System Institutional Review Board approved this study [IRB\#431090-3, 08/19/2013].

We interviewed patients with standardized, open-ended questions (Table 2). A brief description of AIDET and
Hourly Rounding was provided before the interview began. The lead author (TA) conducted each interview for consistency. Interviews were audio-recorded with patient permission and transcribed by one co-author (TR). As recommended for descriptive qualitative studies, a research team conducted an iterative process of coding and analysis. ${ }^{9}$ Due to the relatively small number of transcripts and structured interview schedule, coding was completed using MS Word documents and MS Excel spreadsheets. At the start of the analysis, two researchers (TA, TR) each developed a code set derived from the data ${ }^{8}$ then applied the set of codes to the data systematically. The codebook was refined through consensus discussions, with emerging codes applied in subsequent rounds, with a third researcher (SS) confirming the accuracy and completeness of the data analysis in final coding rounds. ${ }^{10}$ Common themes then were identified by comparing straight descriptions of the phenomena in the sections Overall Hospital Experience, AIDET, and Hourly Rounding. Discrepancies in themes were discussed by the authors until a consensus was achieved.

\section{Results}

Interviews were completed with 14 patients from October to December 2013. The sample was 57\% female with patient ages ranging from 29 to 87 years (average 69 years). Themes identified in this analysis are presented for 4 domains: the patient experience of the hospital stay, AIDET, Hourly Rounding, and unexpected findings.

\section{Patient Experience of the Hospital Stay}

The patients' experiences of their hospital stay were categorized into the best parts of their stay and the worst (Table 3). Participants identified three main themes as the best parts of their hospitalization: staff friendliness, feeling comfortable and comforted by the staff, and personal connections made by the staff. The patients' experience of the worst part of their hospital stay included staff not listening to their concerns or meeting their needs as a patient. In particular, patients mentioned that some staff 
Table 2. Open Ended Interview Questions

\begin{tabular}{|l|l|l|}
\hline \multicolumn{1}{|c|}{ Hospital Stay } & \multicolumn{1}{|c|}{ AIDET } & \multicolumn{1}{c|}{ Hourly Rounding } \\
\hline $\begin{array}{l}\text { What were the best parts of your stay } \\
\text { in the hospital? }\end{array}$ & $\begin{array}{l}\text { How do you feel staff has done using } \\
\text { this new AIDET tool? }\end{array}$ & $\begin{array}{l}\text { Did you notice that a staff person was } \\
\text { coming in to check on you every } \\
\text { hour? }\end{array}$ \\
\hline $\begin{array}{l}\text { What were the worst parts of your } \\
\text { stay in the hospital? }\end{array}$ & $\begin{array}{l}\text { What do you like about the way staff } \\
\text { is communicating with you? }\end{array}$ & $\begin{array}{l}\text { How do you feel about the number of } \\
\text { times the staff was in your room? }\end{array}$ \\
\hline $\begin{array}{l}\text { What could we have done to make } \\
\text { your stay better at the hospital? }\end{array}$ & $\begin{array}{l}\text { What do you dislike about the way } \\
\text { staff is communicating with you? }\end{array}$ & $\begin{array}{l}\text { Describe what staff did when they } \\
\text { checked on you during your hourly } \\
\text { check-up. }\end{array}$ \\
\hline & $\begin{array}{l}\text { How do you think staff could do a } \\
\text { better job communicating with you? }\end{array}$ & $\begin{array}{l}\text { How do you think the hourly check- } \\
\text { ups affected your care during your } \\
\text { hospital stay? }\end{array}$ \\
\hline & $\begin{array}{l}\text { How has the way staff communicated } \\
\text { with you affected your understanding } \\
\text { do to take care of yourself? }\end{array}$ & \\
\hline
\end{tabular}

seemed too busy, rushed or that they did not like to be bothered. Another theme that emerged was the need for emotional support. Patients pointed out that being hospitalized is frightening and scary, and that staff support of these emotional elements was needed to make a positive experience of their hospitalization.

\section{AIDET}

Patients indicated that staff used the AIDET tool most of the time or "always", and that some staff performed AIDET better than others. Patients had varying degrees of recognition and experience with AIDET, but the patients noticed and appreciated staff smiling (acknowledge), introductions, explanations, and asking if there was anything else staff could do for them (thank).

Patients associated acknowledgment with facial expressions, body language and other forms of non-verbal communication, including door knocks, friendliness, and upbeat demeanors. Specifically, patients commented that staff recognized their existence with smiles when entering the room:

I don't think anyone has ever come in here without a smile.

Other patients noted that staff made good eye contact during their interactions with patients:

Looking me in the eyes when they were talking to me. I think that is important. It acknowledges what I am saying.
Patients stated the staff almost always introduced themselves by name and title, as emphasized in the AIDET procedure:

They state their name, and, I'm either the nurse or the aide or whatever for the morning or afternoon.

It was unclear, however, if staff asked patients their preferred names in reciprocation.

A key component of AIDET is a description of the potential duration of a staff-patient encounter, or as one patient noted:

What's going to be done and how long it's going to take.

Most patients could not recall staff telling them how long it would take for the staff member to complete a task or respond to their needs. One patient stated that staff would talk about how long their work shift was going to be:

They'll usually say the hours that they'll be here, 'I'll be here for the next 8 hours, or 12 hours.'

Overall, patients felt the staff did a strong job of explaining what procedures were being done. Nurses explained every task as they were completing it, specifically for routine tasks. Patients felt staff took the time to make sure they understood and explained what was happening in terms the patient could understand, as this patient noted: 
Table 3. Patient Experience of the Hospital Stay

\begin{tabular}{|c|c|}
\hline Best Parts of Stay & Patient Perceptions \\
\hline Friendly, Kind Staff & $\begin{array}{l}\text { "There were very particular nurses who were very conscientious and kind and } \\
\text { supportive. And that was definitely one of the nice things that occurred while I was } \\
\text { here." } \\
\text { "The best parts was the kindliness of the nurses." }\end{array}$ \\
\hline Comfort & $\begin{array}{l}\text { "When you are comfortable and assured, you relax more so the healing process goes } \\
\text { better." } \\
\text { "What made me most comfortable was when staff would get down to my level." }\end{array}$ \\
\hline Connection & $\begin{array}{l}\text { "Most of them have been very personable and tried to make that connection from } \\
\text { their own personal life." } \\
\text { "They made me feel like I was a friend." }\end{array}$ \\
\hline Worst Parts of Stay & Patient Perceptions \\
\hline Hear Me-Help Me & $\begin{array}{l}\text { "I don't think they actually have time to spend any time with the patients." } \\
\text { "These people are busy, and I don't like to bother them." } \\
\text { "Maybe be a little more prompt but I realize the staff have a lot of patients, so I try } \\
\text { to be patient." }\end{array}$ \\
\hline Needs Not Met & $\begin{array}{l}\text { "Anytime I have gone to the hospital, there's always been towels, wash rags, } \\
\text { everything to take a shower, soap, whatever. [this time] Nothing." } \\
\text { "I didn't get any of my medications, and my hydrocodone I need." }\end{array}$ \\
\hline Fearful Emotions & $\begin{array}{l}\text { "The pain and the scare." } \\
\text { "When I get to the hospital I'm always really terrified, you know, scared, because } \\
\text { this has happened to me before, and I'm afraid of dying." }\end{array}$ \\
\hline
\end{tabular}

Very thoroughly. If I was confused they would try to un-confuse me.

Another patient explained:

I feel that the way they were explaining it to me would be the way they would explain to anyone else. Basic enough but thorough enough that it would transpose to anybody.

Some key aspects of the AIDET explanation were mentioned as problem areas. A few patients considered such explanations an expected part of the healthcare providers' role:

They just did it. And I knew what they were doing; it was probably just their routine.

However, some patients were less satisfied with how their illness and its long-term treatment were explained to them versus the explanations for specific tasks. Some patients did not understand their illness, what that illness meant for them, or how to deal with the diagnosis:

When I first got here, I was given a diagnosis outside of what I came here for. And I was left to wonder about that for 12 hours.

Other patients felt that some explanations about their illness were lacking:

The worst part is it's just kind of being, left out of the loop all the time.

Several patients shared the importance of explaining the illness, and not just procedures, in a way that the patient can understand. They stressed that using medical language is not conducive to comprehension:

Oh pretty much in layman terms. Instead of the medical terms, which most people don't understand like me. 
Most patients observed staff using the thank you component of AIDET often, by stating staff thanked them either 'several times', 'quite often', or 'all staff thanked them. Most patients stated they were thanked before the staff left the room:

$$
\begin{aligned}
& \text { All the people that come in always say thank you when they } \\
& \text { leave. }
\end{aligned}
$$

Only two patients did not indicate whether they were thanked or not. Patients did not, however, perceive that the thank you was related to a communication program, but rather because the staff had been taught the right way to say thank you growing up. Others thought patients should technically be thanking staff, not staff thanking patients.

Another theme that came out of the AIDET section of the interview was that staff would ask the patients if they had any questions after explaining what was going on. Some patients noted this technique of staff explanations followed by questions to ensure comprehension and that the patient understood what was said:

And then they always asked if I had any more questions, and then if I do, I've got my answers.

\section{Hourly Rounding}

Patients did not identify staff as addressing the intended "4 Ps" (position, pain, potty, and possessions) during Hourly Rounding. When asked the question, "Describe what staff did when they checked on you during the hourly checkup," patients indicated that the staff member was checking routine care:

They took my vitals, temperature, blood pressure, so forth. Provided medicine to me that I was scheduled to take, sometimes to see how I was feeling.

Several of the patients indicated that the hourly check-ups were not noticeable:

If they were, I didn't know it. They were quiet and subtle about their visits.

Others considered hourly rounds an expected part of a hospitalization:

Because it is just so automatic I think, you really don't notice it.

While patients did not notice the 4 P's they did understand that hospital staff would come in and check on them periodically to assess their needs:

I don't need anything, but at least somebody stopped by and said something.
Many patients responded that if they did need anything, the hospital staff would get it for them:

Sometimes they would stop in and see if I needed something. If there was anything they could do for me.

Unfortunately, a few patients discussed that they did not get their needs met, either through Hourly Rounding or from direct requests for assistance:

I got mad at them one time, I sit on the edge of the bed yelling 'bey you, hey you, hey you' I said I gotta go to the bathroom, I told you 15 minutes ago.

A few of the patients interviewed stated that they chose not to press the call light, but just waited for staff to come back by their room again, because they knew someone would be in soon:

In fact I found myself doing that, just waiting until someone came in to check before I would turn on the light. As another patient noted: I liked the fact that I didn't have to push my nurse button all the time.

However, a few patients did indicate great variability and an often longer than desired wait time when they did push a call light:

$$
\begin{aligned}
& \text { And it might be the only person ringing, and it take them } 20 \\
& \text { minutes to get here. }
\end{aligned}
$$

This seemed to cause distress for some:

I just called her a few minutes ago to go to the bathroom, they ain't made it yet. I better call her again because I really have to go.

Sleep interruptions were a negative aspect of Hourly Rounding. Patients were very adamant that they did not like being woken up in the middle of the night. They also felt it was a burden to have hospital staff check on them when it was night time and they were asleep:

It was more like every two hours when I was asleep but there was still that interruption.

They also commented that the staff was occasionally noisy and rowdy at night, and it was aggravating to be woken up: doing.

If you notice a client is asleep, try to be quieter in what you are

\section{Unexpected Findings}

Loneliness was an unexpected finding from our analysis. One patient spent part of the hospitalization under contact isolation precautions, and described a sense of loneliness experienced as staff communication revealed they did not want to go through putting on the personal protective 
equipment required to see them. Another patient indicated that just having someone to talk to would be nice. She did not specifically say she was lonely, but would like the company:

\section{If you don't have to do anything else we can chat a little.}

When asked if she disliked having someone in her room frequently, she replied:

No, it was company.

Another patient indicated how unsatisfactory it was to feel lonely in the hospital:

There's nothing worse than sitting bere like a dummy and wishing somebody would come in.

Another patient expressed a concern about being alone if discharged too soon:

I didn't really want to go home, because I was afraid I wouldn't have all of you.

Two patients also identified problems with hourly rounding related to hospital staff not maintaining the patient's pain relief regimen. One patient had a pain regimen at home that she followed for her chronic pain. Yet when she entered the hospital, that pain regimen was not recognized as an important part of her home medication list. Another patient who took methadone for chronic pain felt he was categorized by nursing staff as a "drug seeker." The patient and his family perceived that his pain management regimen was not honored because of these nursing staff judgments about his medication:

\section{It was... it seemed like one of those perceived things, 'you're just drug searching'. Well, I'm not drug searching.}

\section{Discussion}

Overall, the results from this study painted a positive picture of the patient experience of hospitalization, particularly in regard to the use of AIDET and Hourly Rounding. These patients believed that most, if not all, hospital staff used AIDET every time they entered the patient's room. Non-verbal communication is a significant element acknowledging a person within the acronym AIDET $^{4}$ and the staff behaviors most frequently mentioned when patients were asked about AIDET were smiling, knocking before entering, and making eye contact. When discussing AIDET, the element of verbal communication most often referenced by the patient was explaining information in a way the patient understands. Patients were much less satisfied with how their illness was explained versus the procedures for specific tasks. Some patients did not understand their illness, what that illness meant for them, or how to deal with the diagnosis. This suggests there is still a communication gap between healthcare providers and patients when it comes to explaining illness diagnosis, as has been found in other studies. ${ }^{1 ; 12}$ Patients also did not identify the duration section of AIDET, suggesting hospital staff were not clearly discussing how long a task would take with the patient. Taking time to state how long a task will take or how long the hospital staff will be caring for the patient may help reduce a patient's anxiety level, as found in other studies of compassionate communication by healthcare professionals. ${ }^{13}$

These patients placed a significant value on the emotional aspects of their hospitalization. These aspects can be enhanced when staff members use communication techniques that provide a connection to patients' feelings of loneliness, anxiety, fear, comfort, and address nonclinical needs. ${ }^{13}$ Patients may experience loneliness in a hospital setting when family and friends may be far away or non-existent, working through daytime hours, or have limited transportation access. Many patients mentioned that they liked when staff checked on them, even if was to just talk or chat with someone. These frequent check-ins may be difficult for patients in contact isolation, where protective equipment and procedures may further limit patient to staff connections. ${ }^{14}$ Therefore patients in contact isolation precautions may require additional attention to ensure they receive the same amount of contact with staff as non-isolation patients. These patients described ways to reduce the distress associated with hospitalization, including (a) explanations in common and plain language, (b) frequent in-person visits to the patient room during daytime/waking hours, (c) active listening by staff, and (d) having a general demeanor that demonstrates caring, kindness, and friendliness.

Patients also discussed clinical needs that were not met such as hygiene, toileting, and communication about their illness. Patients also feel more comfortable in the hospital setting if their daily home routines and schedules are maintained. Clearly, patients require assistance from hospital personnel with fundamental self-care tasks such as eating, changing, bathing, and walking. ${ }^{15}$ These are needs that should be attended to in a timely manner. These findings support previous research done to encourage individualized patient care, which reduces patient anxiety, improves communication, encourages teamwork, and signals to the patient that everyone is working together. ${ }^{4}$

Hourly rounding is intended to check on patients between scheduled nursing tasks, such as conducting vital signs every four to eight hours. Rounding is intended to meet the patients predetermined needs such as pain, toileting, positioning, and possessions such as tissues, beverages, or phones within reach, and provide patient centered care. ${ }^{15}$ Patients were unable to confirm that rounding occurred on an hourly basis during waking hours but knew that 
someone was checking on them frequently. Staff may not have used the term "rounding" to signify the purpose of their visit, or patients interpreted as staff "checking-in" during the visit. This could signify a lack of consistency, absence of explaining when staff would be back to check on the patient, or a lack of importance to the patient.

Hourly rounding with a purpose has been found to reduce the number of call lights by reaching the patients need to use the restroom, manage pain, and adjust positioning before the need becomes present. ${ }^{16}$ Previous research documents that nurses are called into a patient's room 12 15 times a day for needs such as pain, toileting, and positioning. ${ }^{4}$ Ford ${ }^{2}$ asserted that call lights in her study were reduced $51 \%$ after introducing hourly rounding to their organization. Although our interviews showed that hourly rounding happened, some crucial needs such as pain control, toileting, and personal hygiene needs were not being met consistently. However, patients in this qualitative study supported previous quantitative research by our organization that showed reduced use of call lights. Patients noted that they would wait for a staff member to come in instead of using the call light because hourly rounding was happening on a routine basis.

Another finding is that hourly rounding processes on inpatient units must be robust and completed with a purpose. Hourly rounding with a purpose means that hospital staff state the purpose of their visit, "rounding," and ask the patient about the "4 Ps" (Pain, Potty, Position, and Possessions). This study indicates a more formal process for hourly rounding may result in better understanding and utilization (i.e., less call light usage).

Patients were very adamant that they did not like to have their sleep interrupted, an unwanted side effect of hourly rounding. There is supporting evidence that enhancing sleep and reducing noise are vital nighttime responsibilities for hospital staff. Sleep deprivation should be a top priority for nurses at the unit level in regards to their patients because sleep deprivation is associated with negative health outcomes. ${ }^{17}$ This also supports the importance of the Center for Medicare and Medicaid Services (CMS) H-CAHPS survey question regarding the quietness of the hospital environment at night. Nurses play key roles in ensuring noise reduction for patients to enable them to sleep better and promote healing. ${ }^{18}$ Comments regarding interruptions during the night suggest it may be necessary to revisit the use and frequency of hourly rounding during the nighttime hours.

The results identify the importance of communication and the need for staff skills in providing comfort, alleviating fear, and improving understanding. Organizations need to have clear staff expectations regarding communication and connecting with patients. As this study demonstrates, these types of skills are considered by hospitalized patients to be a basic requirement for a positive experience. Similarly, this study implies the need to provide care based on the needs of the individual patient, since each patient has different expectations and needs regarding information, communication, personal care, and emotional support. A comprehensive assessment of patient goals and needs would help staff to meet patient expectations. Staff should be sure to educate the patient on not only what they are doing but why the care is necessary and how it will affect the patient's illness. This study suggests that patientcentered care and patient experience can be enhanced by improved patient understanding of their illness. However, additional research is needed to explore patient perceptions of their illness and how to enhance that understanding.

\section{Conclusion}

While the results of this study are not generalizable, they suggest a number of implications for the patient experience that warrant further investigation. Study results indicate that patients want kind, friendly, and helpful hospital staff that provide them with comfort while they are hospitalized. These types of behaviors can reduce the patient's anxiety and fear, therefore improving their experience during hospitalization. Patients also need to have their disease process and self-management explained to them in a way they can understand. Findings suggest more intentional use of AIDET and Hourly Rounding can maximize the benefits of these tools by making their use and purpose more apparent to patients. This study identifies the patient experience in the hospital for one, mid-sized community hospital. Further research is needed, as the patients' perception of their experiences is important to improving patient-centered care and improving the patient experience.

\section{References}

1. Dempsey C, Reilly B, Buhlman N. Improving the patient experience: real-world strategies for engaging nurses. J Nurs Adm 2014; 44: 142-151.

2. Ford BM. Hourly rounding: a strategy to improve patient satisfaction scores. Medsurg Nurs 2010;19:188191.

3. Cooper RL, Lee JY. Using huddles to enhance patient experience: organizational huddles improve teamwork and patient care. Healthcare executive 2012; 28: 48-50.

4. Studer Q, Robinson BC, Cook K. The HCAHPS handbook: Hardwire your hospital for pay-for-performance success. Gulf Breeze, FL: Fire Starter Publishing, 2010.

5. Scott J. Utilizing AIDET and other tools to increase patient satisfaction scores. Radiol Manage 2011;34:2933.

6. Ruffinen MAZ. 10 steps to improve patient satisfaction. Nursing 2007; 37: 22-24. 
7. Deitrick LM, Baker K, Paxton H, Flores M, Swavely D. Hourly rounding: challenges with implementation of an evidence-based process. J Nurs Care Qual 2012; 27: 13-19.

8. Sandelowski M. Whatever happened to qualitative description? Res Nurs Health 2000; 23: 334-340.

9. Khandkar SH. Open coding. http://pages.cpsc.ucalgary.ca/ saul/wiki/uploads/C PSC681/open-coding.pdf_Published 2009. Accessed April 15, 2015.

10. MacQueen KM, McLellan E, Kay K, Milstein B. Codebook development for team-based qualitative analysis. Cult Anthrop Meth 1998; 10: 31-36.

11. Grace VM. Problems of communication, diagnosis, and treatment experienced by women using the New Zealand health services for chronic pelvic pain: a quantitative analysis. Health Care Women Int 1995; 16: 521-535.

12. Gulbrandsen P, Madsen HB, Benth JS, Laerum E. Health care providers communicate less well with patients with chronic low back pain: a study of encounters at a back pain clinic in Denmark. Pain 2010; 150: 458-461.

13. Fogarty LA, Curbow BA, Wingard JR, McDonnell K, Somerfield MR. Can 40 seconds of compassion reduce patient anxiety? J Clin Oncol 1999; 17: 371-379.

14. Barratt RL, Shaban R, Moyle W. Patient experience of source isolation: lessons for clinical practice. Contemp Nurse 2011; 39: 180-193.

15. Blakley D, Kroth M, Gregson J. The impact of nurse rounding on patient satisfaction in a medical-surgical hospital unit. Medsurg Nurs 2011; 20: 327-332.

16. Berg K, Sailors C, Reimer R, O'Brien Y, Ward-Smith P. Hourly rounding with a purpose. Iowa Nurse Reporter 2011; 24: 12-14.

17. Pilkington S. Causes and consequences of sleep deprivation in hospitalised patients. Nurs Stand 2013; 27: 35-42.

18. Murphy G, Bernardo A, Dalton J. Quiet at night: implementing a nightingale principle. Am J Nurs 2013; 113: 43-51. 